\title{
Estimating Maximum Significant Wave Height and Dominant Wave Period inside Tropical Cyclones
}

\author{
PAUL A. HWANG \\ Remote Sensing Division, Naval Research Laboratory, Washington, D.C. \\ EDWARD J. WALSH \\ NOAA/Earth System Research Laboratory/Physical Sciences Division, Boulder, Colorado
}

(Manuscript received 18 December 2017, in final form 30 April 2018)

\begin{abstract}
Making use of the fetch- and duration-limited nature of wind-wave growth inside tropical cyclones, an algorithm is developed to estimate the maximum significant wave height and dominant wave period of surface waves generated by tropical cyclone wind fields. The results of the maximum significant wave height and dominant wave period are further approximated by simple power functions of the maximum wind speed. The exponents of the power functions are almost constant, and the proportionality coefficients can be approximated by second-order polynomial functions of the radius of maximum wind speed (RMW). The predicted maximum values agree well with results derived from simultaneous wind and wave measurements obtained during 11 hurricane reconnaissance and research missions in six hurricanes.
\end{abstract}

\section{Introduction}

Tropical cyclones (TCs) are among the most hazardous natural disasters. They cause tremendous damage and pose extreme challenges for ship operations. Presently, satellite and other TC monitoring efforts primarily address the wind velocity; there is no operational spaceborne capability for similar synoptic and continuous observations of wave parameters. To properly evaluate the damage potential of a TC, it is critical to consider not only wind but also sea state parameters such as the significant wave height and dominant wave period.

Recent analyses of the wind and wave data collected during several hurricane reconnaissance and research missions have established that the wave development inside TCs follows essentially the same fetch- or durationlimited principle governing the wave growth under steady wind forcing conditions (Hwang 2016; Hwang and Walsh 2016; Hwang and Fan 2017). This is an important result because at the foundation of the fetch- or duration-limited wave growth is a pair of dimensionless equations describing the growth of wave height and wave period subject to wind forcing. The three most important wind and

Corresponding author: Dr. Paul A. Hwang, paul.hwang@nrl. navy.mil wave parameters (the wind-wave triplets: surface wind speed $U_{10}$, significant wave height $H_{s}$, and dominant wave period $T_{p}$ ) are thus connected by two equations for a given fetch or duration. Defining the fetch or duration of a TC wind field thus holds the key to accessing the robust and versatile wind-wave growth functions for resolving ( $U_{10}$ and $H_{s}$ and $\left.T_{p}\right)$ with only $\left(U_{10}\right.$ or $H_{s}$ or $\left.T_{p}\right)$ measured.

Through a reverse-engineering procedure, Hwang and Fan (2017) developed a scaling model of the effective fetch and duration of TC wind fields using the simultaneous wind and wave data collected from four hurricane reconnaissance and research missions during Bonnie 1998 and Ivan 2004 (Wright et al. 2001; Fan et al. 2009). The main features of the fetch and duration scaling model are 1) the fetch and duration increase linearly with the radial distance $r$ from the TC center along any radial transect, analogous to a circular race track; 2) the slope and intercept of the linear radial dependency can be formulated as Fourier series of the azimuth angle $\phi$, with consideration of the continuous and cyclical azimuthal dependency; and 3) the derived Fourier coefficients show quasi-linear dependency on the radius of maximum wind speed (RMW) $r_{m}$. It is recognized that the circular race track paradigm is only a coarse approximation to facilitate the estimation of sea state parameters using the hurricane wind input. 
With the scaling model supplying the fetch and duration in the wind-wave growth functions, $H_{s}$ and $T_{p}$ are given in simple algebraic equations of $U_{10}$ and $r$ along each radial transect. Furthermore, the radial dependency of wind speed can be approximated by a power function of $r$; therefore, the formulas for $H_{s}$ and $T_{p}$ along a radial transect are given as algebraic equations of $r$ alone. Their maximum values, $H_{s \max \phi}$ and $T_{p \max \phi}$, can be obtained by seeking the locations where the radial gradients of the algebraic functions become zero. The search of the maximum $H_{s}$ and $T_{p}$ inside the 2D TC coverage area is rendered to be the search of the maxima of 1D (azimuthal) $H_{s \max \phi}$ and $T_{p \max \phi}$.

The similarity relationships of fetch- and durationlimited wind-wave development are rather robust, and they can be formulated with different reference scaling wind speeds. For example, Hwang (2006) presents the results with different velocity scalings, including the surface wind speed $U_{10}$, the wind friction velocity $u_{*}$, and the wind velocity at the elevation equal to one-half of the dominant wavelength $U_{\lambda / 2}$. The wind speed in the hurricane reconnaissance simultaneous wind and wave data is measured at flight levels mostly between 1500 and $3100 \mathrm{~m}$, but Hwang and Fan (2017) misinterpreted it as the surface $(10 \mathrm{~m})$ value. The resulting scaling model for the effective fetch and duration should therefore be applied with the flight-level wind speed. There are many publications on the subject of adjusting the flight level to the surface wind (e.g., Powell 1980; Dunion et al. 2003; Franklin et al. 2003; Uhlhorn and Black 2003; Uhlhorn et al. 2007). In this paper, we use a correction factor of 0.9 for the eyewall region based on the analysis of the vertical wind profiles derived from GPS dropwindsondes (Franklin et al. 2003). Further discussion on the subject is presented in section 5 .

Section 2 describes the fetch- and duration-limited wind-wave growth serving as the theoretical foundation of the algorithm. Section 3 presents the parametric models of surface wind speed, significant wave height, and dominant wave period, with emphasis on the $r$ dependence. The result is used to develop the algorithm for estimating the maximum significant wave height and dominant wave period. Section 4 discusses the computational results for storm intensity $U_{10 \max }$ ranging from 20 to $80 \mathrm{~m} \mathrm{~s}^{-1}$ and $r_{m}$ from 10 to $100 \mathrm{~km}$. The predicted maximum wave parameters $\left(H_{s \max }\right.$ and $\left.T_{p \max }\right)$ are further approximated by power functions of $U_{10 \max }$ with the proportionality coefficients and exponents depending on $r_{m}$. The predicted maximum values compare well with those derived from simultaneous wind and wave observations in 11 hurricane reconnaissance and research missions during six hurricanes. Section 5 presents a discussion of the fetch- and duration-limited wind-wave similarity functions scaled with different reference wind speeds, in particular, the flight level versus 10-m surface wind. This discussion is prompted by the misinterpretation of the hurricane hunter wind data in Hwang and Fan (2017) as described in the last paragraph. Section 6 offers a summary.

\section{Fetch- and duration-limited wind-wave growth}

From 1998 to 2005, the NASA Scanning Radar Altimeter (SRA; Walsh et al. 1985, 1989) was deployed in NOAA hurricane reconnaissance and research missions to measure the ocean surface directional wave spectra inside TCs. Over the years, detailed analyses of four sets of data in deepwater conditions have been published (Wright et al. 2001; Moon et al. 2003; Fan et al. 2009). Recent analyses of these simultaneous and collocated wind and wave data (Hwang 2016; Hwang and Walsh 2016; Hwang and Fan 2017) have established that the wave development inside TCs follows the same fetch- and duration-limited wind-wave growth functions established with data from field experiments conducted in nonhurricane conditions (e.g., Sverdrup and Munk 1947; Hasselmann et al. 1973, 1976; Donelan et al. 1985; Hwang and Wang 2004; Hwang et al. 2011).

Wind-wave generation has been among the most extensively investigated subjects in surface wave research. Efforts during World War II and prior were documented in the technical report by Sverdrup and Munk (1947). By that time the concept of fetch- and duration-limited wind-wave growth had been well established, as summarized in the dimensionless plots of their Figs. 6 and 7 describing the growth of wave phase speed and wave height as wind speed, fetch, or duration increases.

In subsequent years, the wave research gradually pivoted to wave spectral representation in recognition of the multiple oscillation scales in the ocean surface wave motion. The spectral variance and dominant wave frequency became the characteristic wave properties in wind-wave growth studies. The fetch- and duration-limited growth are represented by fetch-limited similarity $\eta_{\#}\left(x_{\#}\right)$ and $\omega_{\#}\left(x_{\#}\right)$ and durationlimited similarity $\eta_{\#}\left(t_{\#}\right)$ and $\omega_{\#}\left(t_{\#}\right)$, where the subscript \# indicates dimensionless variables: $\eta_{\#}=\eta_{\mathrm{rms}}^{2} g^{2} / U_{10}^{4}$, $\omega_{\#}=\omega_{p} U_{10} / g, x_{\#}=x_{f} g / U_{10}^{2}$, and $t_{\#}=t_{d} g / U_{10}, x_{f}$ is fetch, $t_{d}$ is duration, the root-mean-square (rms) wave elevation $\eta_{\mathrm{rms}}$ is related to the significant wave height by $H_{s}=4 \eta_{\mathrm{rms}}$, the angular frequency of the spectral peak component $\omega_{p}$ is $2 \pi / T_{p}$, and $g$ is the gravitational acceleration.

Hwang and Wang (2004) obtain the first- and secondorder fitting equations for the combined data from five fetch-limited field experiments conducted under quasisteady wind forcing and near-neutral stability conditions (Burling 1959; Hasselmann et al. 1973, 1976; Donelan et al. 1985; Dobson et al. 1989; Babanin and Soloviev 1998); these fetch-limited datasets are collectively referred to as the BHDDB data. The simultaneous wind and wave data 
from hurricane reconnaissance missions show that the wave development in a TC falls in the region where the first- and second-order growth functions overlap (Hwang 2016; Hwang and Walsh 2016; Hwang and Fan 2017), and the simpler first-order fitted equations can be applied:

$$
\begin{aligned}
& \eta_{\#}=6.19 \times 10^{-7} x_{\#}^{0.81}, \\
& \omega_{\#}=11.86 x_{\#}^{-0.24} .
\end{aligned}
$$

Through the connection between fetch and duration by the group velocity, which is the energy propagation velocity of the wave field, the fetch-limited growth curves can be mathematically converted to the duration-limited growth curves:

$$
\begin{aligned}
\eta_{\#} & =1.27 \times 10^{-8} t_{\#}^{1.06}, \\
\omega_{\#} & =2.94 t_{\#}^{-0.34} .
\end{aligned}
$$

Leaving the dimensional variables explicitly in the equations, (1) and (2) are rewritten as

$$
\begin{aligned}
& \frac{H_{s}^{2} g^{2}}{16 U_{10}^{4}}=6.19 \times 10^{-7}\left(\frac{x_{f} g}{U_{10}^{2}}\right)^{0.81}, \\
& \frac{2 \pi U_{10}}{T_{p} g}=11.86\left(\frac{x_{f} g}{U_{10}^{2}}\right)^{-0.24}, \text { and } \\
& \frac{H_{s}^{2} g^{2}}{16 U_{10}^{4}}=1.27 \times 10^{-8}\left(\frac{t_{d} g}{U_{10}}\right)^{1.06}, \\
& \frac{2 \pi U_{10}}{T_{p} g}=2.94\left(\frac{t_{d} g}{U_{10}}\right)^{-0.34} .
\end{aligned}
$$

To make use of the fetch- and duration-limited wave growth equations, it is necessary to define the fetch $x_{f}$ and duration $t_{d}$ of a TC wind field. Through reverse engineering using the simultaneous wind and wave data from four hurricane reconnaissance and research missions, Hwang and Fan (2017) obtain a scaling model of the effective fetch and duration. The analyses show that in the main region of the TC coverage area (tentatively defined as $50 \leq r \leq$ $200 \mathrm{~km}$ ) the fetch and duration can be represented by linear functions of the radial distance $r$ from the TC center:

$$
x_{\eta x}(r, \phi)=s_{\eta x}(\phi) r+I_{\eta x}(\phi), \quad x_{\omega x}(r, \phi)=s_{\omega x}(\phi) r+I_{\omega x}(\phi)
$$

and

$$
t_{\eta t}(r, \phi)=s_{\eta t}(\phi) r+I_{\eta t}(\phi), \quad t_{\omega t}(r, \phi)=s_{\omega t}(\phi) r+I_{\omega t}(\phi),
$$

where $\phi$ is the azimuth angle referenced to the TC heading, positive counterclockwise (CCW). Hwang and Fan (2017) assign different fetches and durations for wave height and wave period to account for the observed systematic deviation of the hurricane data from the ideal growth functions in different TC azimuthal regions (Hwang and Walsh 2016). The distinction is denoted by the dual subscripts of fetch $x_{i j}$ or duration $t_{i j}$; that is, the subscripts $\eta x$ and $\omega x$ indicate that the associated variables are applicable to $\eta_{\#}\left(x_{\#}\right)$ and $\omega_{\#}\left(x_{\#}\right)$, respectively. Similarly, $\eta t$ and $\omega t$ indicate that the associated variables are applicable to $\eta_{\#}\left(t_{\#}\right)$ and $\omega_{\#}\left(t_{\#}\right)$, respectively.

The intercepts $I$ and slopes $s$ of the linear functions in (5) and (6) are then expressed in Fourier series:

$$
q=a_{0, q}+2 \sum_{n=1}^{N}\left(a_{n, q} \cos n \phi+b_{n, q} \sin n \phi\right),
$$

where $q$ can be $s_{\eta x}, I_{\eta x}, s_{\omega x}, I_{\omega x}, s_{\eta t}, I_{\eta t}, s_{\omega t}$, or $I_{\omega t}$.

The harmonics $a_{n, q}$ and $b_{n, q}$ display a systematic quasilinear variation with the $r_{m}$ :

$$
Y=p_{1 Y} r_{m}+p_{0 Y},
$$

where $Y$ represents $a_{n, q}$ and $b_{n, q}$ in (7). The fitting coefficients $p_{1 Y}$ and $p_{0 Y}$ are listed in Table 3 in Hwang and Fan (2017).

Rearranging (3) and (4), $H_{s}$ and $T_{p}$ inside TCs can be written as (Hwang 2016)

$$
\begin{aligned}
H_{s} & =8.10 \times 10^{-4} U_{10}^{1.19} x_{\eta x}^{0.405}, \\
T_{p} & =9.28 \times 10^{-2} U_{10}^{0.526} x_{\omega x}^{0.237} \text { and } \\
H_{s} & =1.55 \times 10^{-4} U_{10}^{1.47} t_{\eta t}^{0.531}, \\
T_{p} & =3.53 \times 10^{-2} U_{10}^{0.690} t_{\omega t}^{0.310} .
\end{aligned}
$$

[As noted in section 1, Hwang and Fan (2017) misinterpreted the hurricane hunter flight-level wind as the surface wind, and the developed fetch and duration model is in fact applicable to the flight-level wind instead of the surface wind. This point is further discussed in section 5 . The algorithm for maximum wave properties, however, is formulated with $U_{10}$ as the reference wind speed.]

\section{Algorithm of maximum significant wave height and dominant wave period}

Because fetch and duration are linear functions of $r$ [(5) and (6)], (9) and (10) are in the general form of

$Z(\phi, r)=K U_{10}^{\alpha}[I(\phi)+s(\phi) r]^{\beta}, \quad 50 \leq r \leq 200 \mathrm{~km}$,

where $Z$ is a sea state variable (i.e., $H_{s}$ or $T_{p}$ ), and $I$ and $s$ are the intercept and slope of the effective fetch or duration. The proportionality constant, and the exponents of the wind speed and fetch or duration in (9) and (10), are given as $K, \alpha$, and $\beta$ in (11). 

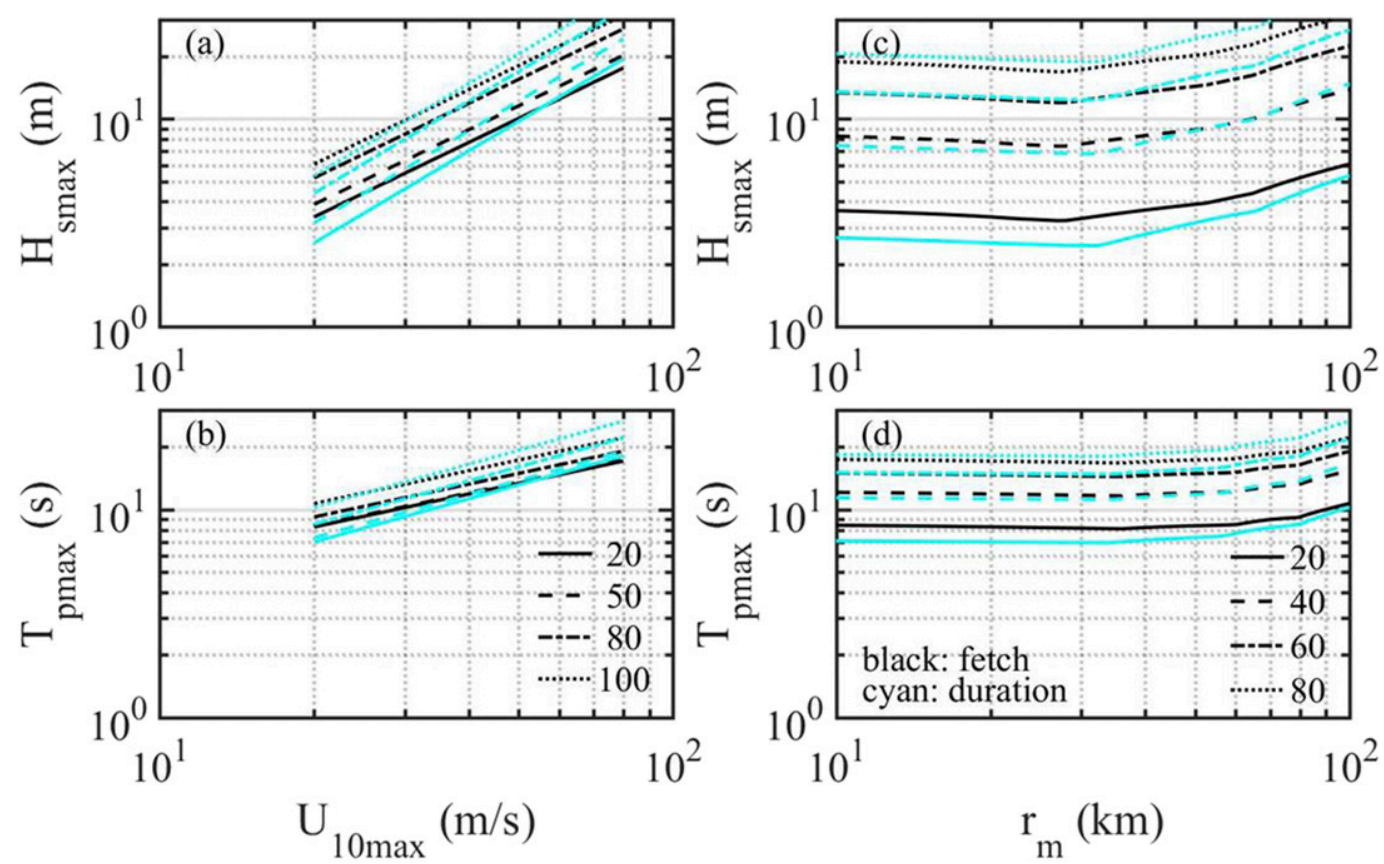

FIG. 1. The (a) $H_{s \max }$ and (b) $T_{p \max }$ results for $r_{m}=20,50,80$, and $100 \mathrm{~km}$ plotted as functions of $U_{10 \max }$. The (c) $H_{s \max }$ and (d) $T_{p \max }$ results for $U_{10 \max }=20,40,60$, and $80 \mathrm{~m} \mathrm{~s}^{-1}$ plotted as functions of $r_{m}$. Results computed with the fetch- and duration-limited functions are shown with black and cyan curves, respectively.

For the purpose of estimating the maximum significant wave height and dominant wave period without the necessity of computing the waves over the full TC coverage area, we seek a simple expression of the wind field radial dependence such as the modified Rankine vortex (e.g., Holland 1980; Holland et al. 2010). Because the wind speed and fetch or duration both increase monotonically from the TC center toward the $r_{m}$, the wave growth inside $r \leq r_{m}$ is monotonic with the maximum occurring at $r_{m}$. The search for the maximum $H_{s}$ and $T_{p}$ inside the TC coverage area, therefore, needs only be carried out in the region $r \geq r_{m}$, where the wind profile can be approximated by

$$
U_{10}(\phi, r)=U_{10 \max \phi}\left(\frac{r}{r_{m}}\right)^{-0.5}, \quad r \geq r_{m},
$$

where $U_{10 \max \phi}$ is the maximum wind speed along the transect with azimuth angle $\phi$ and (11) can be expressed with $r$ as the only dependent variable along any radial transect:

$Z(\phi, r)=K U_{10 \max \phi}^{\alpha}\left(\frac{r}{r_{m}}\right)^{-0.5 \alpha}[I(\phi)+s(\phi) r]^{\beta}$.

The radial location $r_{*}$ where the maximum value of $Z$ occurs along a radial transect of constant $\phi$ (i.e., $Z_{\max \phi}=$ $H_{s \max \phi}$ or $T_{p \max \phi}$ ) can be obtained by taking $d Z / d r=0$, which produces

$$
r_{*}(\phi)=\frac{0.5 \alpha I(\phi)}{\beta s(\phi)-0.5 \alpha s(\phi)} .
$$

The task of finding the maximum significant wave height or dominant wave period $\left(Z_{\max }=H_{s \max }\right.$ or $\left.T_{p \max }\right)$ of the 2D wave field inside TCs is reduced to searching for the maximum of the $1 \mathrm{D} Z_{\max \phi}=Z\left[\phi, r_{*}(\phi)\right]$ :

$$
Z\left[\phi, r_{*}(\phi)\right]=K U_{10 \max \phi}^{\alpha}\left[\frac{r_{*}(\phi)}{r_{m}}\right]^{-0.5 \alpha}\left[I(\phi)+s(\phi) r_{*}(\phi)\right]^{\beta}
$$

\section{Results and discussion}

\section{a. Dependence on hurricane properties}

The $H_{s \max }$ and $T_{p \max }$ results obtained from the algorithm described in section 3 are calculated for $r_{m}$ ranging from 10 to $100 \mathrm{~km}$ and $U_{10 \max }$ ranging from 20 to $80 \mathrm{~m} \mathrm{~s}^{-1}$. The result based on azimuth-independent $U_{10 \max \phi}$ (i.e., $U_{10 \max \phi}=U_{10 \max }$ ) is described for the purpose of providing a conservative estimation. Employing an azimuth-dependent $U_{10 \max \phi}$ may decrease slightly the magnitude of the calculated $H_{s \max }$ and $T_{p \max }$.

Figures $1 \mathrm{a}$ and $1 \mathrm{~b}$ display the $H_{s \max }$ and $T_{p \max }$ dependence on $U_{10 \max }$ for $r_{m}=20,50,80$, and $100 \mathrm{~km}$, and Figs. $1 \mathrm{c}$ and $1 \mathrm{~d}$ show their $r_{m}$ dependency for 

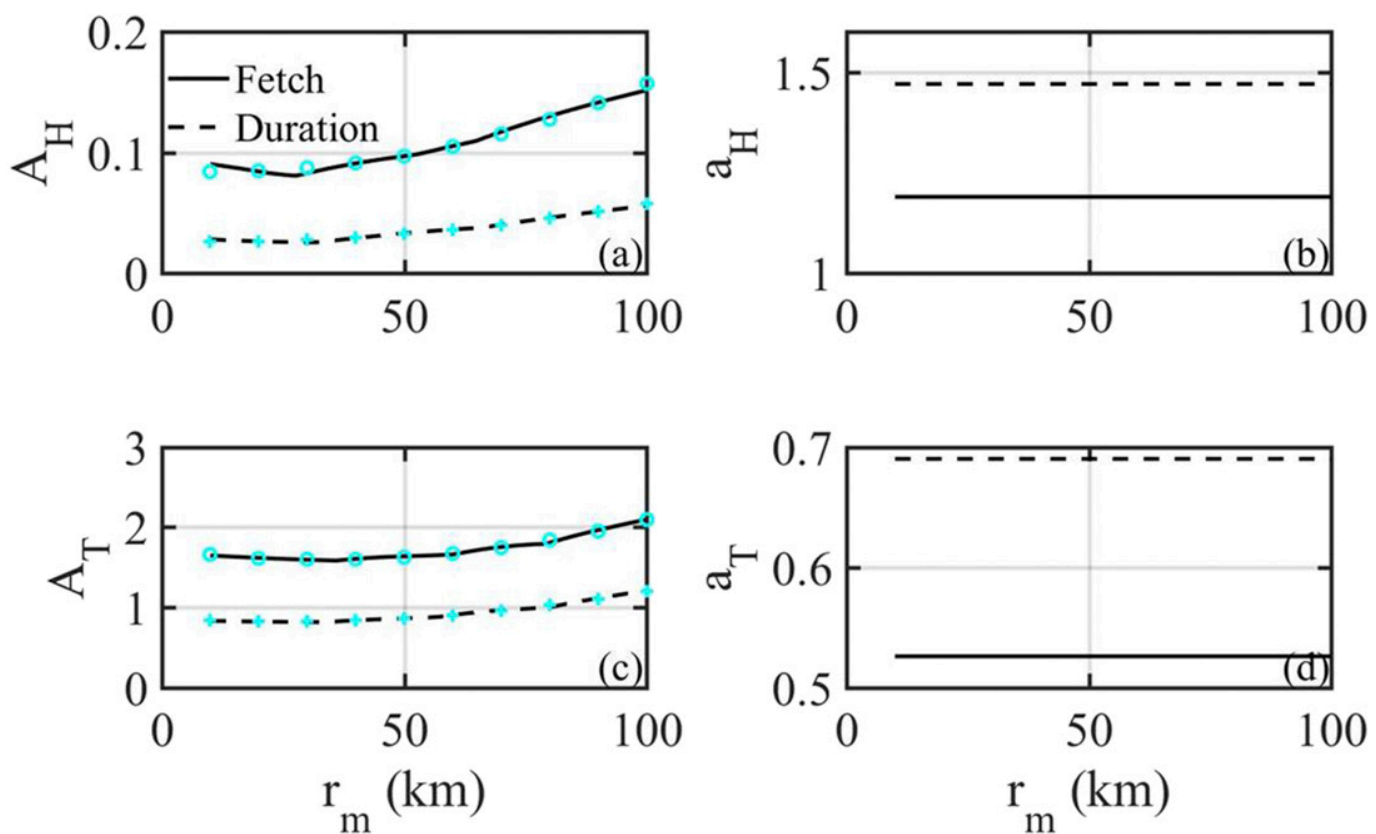

FIG. 2. The proportionality coefficients and exponents for the power function [(16)] describing the dependency of $H_{s \max }$ and $T_{p \max }$ on $U_{10 \max }$ and $r_{m}$ : (a) $A_{H x}$ and $A_{H t}$, (b) $a_{H x}$ and $a_{H t}$, (c) $A_{T x}$ and $A_{T t}$, and (d) $a_{T x}$ and $a_{T t}$. In (a) and (c), the second-order polynomial approximations from (17) of the proportionality coefficients are illustrated with cyan symbols.

$U_{10 \max }=20,40,60$, and $80 \mathrm{~m} \mathrm{~s}^{-1}$. The results computed with the fetch- and duration-limited functions are shown with black and cyan curves, respectively. The two sets of computations are qualitatively similar except that the duration results exhibit a wider range of the estimates.

The computed $H_{s \max }$ and $T_{p \max }$ increase with $U_{10 \max }$ monotonically, and they can be approximated by power functions:

$$
Q_{q}\left(U_{10}, r_{m}\right)=A_{Q q}\left(r_{m}\right) U_{10 \max }^{a_{Q q}\left(r_{m}\right)}
$$

where $Q$ can be $H$ or $T$ to represent $H_{s \max }$ or $T_{p \max }$, and $q$ can be $x$ or $t$ to indicate whether $Q$ is derived from the fetch or duration function.

Using the computed $H_{s \max }$ and $T_{p \max }$ with $r_{m}$ from 10 to $100 \mathrm{~km}$ and $U_{10 \max }$ from 20 to $80 \mathrm{~m} \mathrm{~s}^{-1}$ as the database (Fig. 1), proportionality coefficients and exponents derived from least squares fitting of (16) are shown in Fig. 2. The exponents are basically constant: $a_{H x}=1.19$, $a_{H t}=1.47, a_{T x}=0.53$, and $a_{T t}=0.69$. The $A_{Q q}$ dependency on $r_{m}$ can be represented by second-order polynomials:

$$
A_{Q q}\left(r_{m}\right)=p_{2} r_{m}^{2}+p_{1} r_{m}+p_{0} .
$$

The fitting coefficients $\left(p_{2}, p_{1}, p_{0}\right)$ are $\left(1.10 \times 10^{-5}\right.$, $\left.-2.99 \times 10^{-4}, 9.76 \times 10^{-2}\right)$ for $A_{H x},\left(4.47 \times 10^{-6}\right.$, $\left.-8.20 \times 10^{-5}, 3.08 \times 10^{-2}\right)$ for $A_{H t},\left(1.19 \times 10^{-4}\right.$, $\left.-7.94 \times 10^{-3}, 1.82\right)$ for $A_{T x}$, and $\left(7.46 \times 10^{-5},-3.80 \times 10^{-3}\right.$, $9.29 \times 10^{-1}$ ) for $A_{T t}$. The $A_{H x}, A_{H t}, A_{T x}$, and $A_{T t}$ values calculated from the fitted second-order polynomials are shown in Figs. 2a and 2c with cyan symbols.

\section{b. Comparison with hurricane hunter measurements and error estimates}

Over the years, many hurricane reconnaissance and research missions carried the NASA SRA to measure the 3D surface wave topography inside TCs. Eleven of the datasets have been processed to get the detailed directional wave spectra, from which $H_{s}$ and $T_{p}$ are calculated (Table 1 ). The fetch and duration scaling model and the algorithm for maximum wave parameters described in sections 2 and 3 are based on the first four datasets in Table 1. These were collected in deep water from two hurricanes (Bonnie in 1998 and Ivan in 2004) along 6-12 radial transects, with the number of wave spectral observations ranging from 233 to 600 per observation period. Figure 3 shows the comparison of $H_{s \max }$ and $T_{p \text { max }}$ predicted by the algorithm with those observed in the four hurricane reconnaissance missions with green symbols.

Also shown in Fig. 3 with red symbols are results from the remaining seven datasets in Table 1 , including one 
TABLE 1. Some basic information related to the hurricane hunter datasets used in this paper.

\begin{tabular}{|c|c|c|c|c|c|c|c|c|}
\hline $\begin{array}{c}\text { File ID } \\
\text { (NameYear-Day) }\end{array}$ & $\begin{array}{l}U_{\mathrm{FLmax}} \\
\left(\mathrm{m} \mathrm{s}^{-1}\right)\end{array}$ & $H_{s \max }(\mathrm{m})$ & $T_{p \max }(\mathrm{s})$ & Start time & End time & $V_{h}\left(\mathrm{~m} \mathrm{~s}^{-1}\right)$ & $\phi_{h}\left({ }^{\circ} \mathrm{N}\right)$ & $r_{m}(\mathrm{~km})$ \\
\hline Bonnie1998-24 & 45.7 & 10.9 & 13.3 & 2029 UTC 24 Aug 1998 & 0144 UTC 25 Aug 1998 & 4.5 & 13 & 74 \\
\hline Ivan2004-09 & 74.0 & 12.7 & 15.2 & 1615 UTC 9 Sep 2004 & 2010 UTC 9 Sep 2004 & 5.6 & 62 & 13 \\
\hline Ivan2004-12 & 59.5 & 12.0 & 13.8 & 1039 UTC 12 Sep 2004 & 1541 UTC 12 Sep 2004 & 4.3 & 65 & 17 \\
\hline Ivan2004-14 & 69.6 & 13.1 & 14.4 & 2009 UTC 14 Sep 2004 & 0249 UTC 15 Sep 2004 & 4.8 & 25 & 42 \\
\hline Bonnie1998-26 & 38.8 & 10.8 & 14.3 & 1638 UTC 26 Aug 1998 & 2235 UTC 26 Aug 1998 & 4.5 & 0 & 74 \\
\hline Floyd1999-13 & 61.4 & 12.2 & 14.2 & 2012 UTC 13 Sep 1999 & 0051 UTC 14 Sep 1999 & 5.0 & 70 & 32 \\
\hline Humberto2001-23 & 49.0 & 6.5 & 10.7 & 2005 UTC 23 Sep 2001 & 2357 UTC 23 Sep 2001 & 4.5 & -10 & 32 \\
\hline Humberto2001-24 & 36.9 & 6.0 & 10.8 & 2054 UTC 24 Sep 2001 & 0058 UTC 25 Sep 2001 & 6.5 & -50 & 42 \\
\hline Lili2002-30 & 36.7 & 5.7 & 11.2 & 1922 UTC 30 Sep 2002 & 0003 UTC 1 Oct 2002 & 4.0 & 45 & 75 \\
\hline Frances2004-31 & 70.2 & 12.1 & 14.7 & 1641 UTC 31 Aug 2004 & 1922 UTC 31 Aug 2004 & 5.8 & 80 & 32 \\
\hline Frances2004-01 & 62.5 & 10.0 & 14.5 & 1639 UTC 1 Sep 2004 & 2011 UTC 1 Sep 2004 & 5.5 & 70 & 25 \\
\hline
\end{tabular}

collected during Bonnie's 1998 landfall (Walsh et al. 2002) and six previously unpublished (one each from Floyd in 1999 and Lili in 2002, and two each from Humberto in 2001 and Frances in 2004); the number of spectral observations per observation period ranges from 79 to 213. The agreement between the predicted $H_{s \max }$ and $T_{p \max }$ with observed values in these seven sets is similar to the four sets used in the algorithm development. Overall, the mean and standard deviation of the ratio between predicted and measured values are 1.13 and 0.20 , respectively, for $H_{s \max }$, and 1.01 and 0.07 for $T_{p \max }$. Separately, the mean and standard deviation of the ratio between the predicted and measured values for the first four datasets are 1.06 and 0.13 for $H_{s \max }$, and 1.03 and 0.03 for $T_{p \max }$; for the last seven datasets, they are 1.17 and 0.21 for $H_{s \max }$, and 1.01 and 0.08 for $T_{p \max }$.

Figure 4 shows contour maps of $H_{s \max }\left(U_{10 \max }, r_{m}\right)$ and $T_{p \max }\left(U_{10 \max }, r_{m}\right)$, which is an alternative display of the dependency of maximum wave parameters on $U_{10 \max }$ and $r_{m}$, as illustrated in Fig. 1. Solid and dashed lines show the results computed with the fetch- and durationlimited functions, respectively. The red and green markers show the maximum significant wave height and dominant wave period data (with the corresponding values printed beside the markers) based on the 11 hurricane reconnaissance and research missions as described in the previous two paragraphs. In general, the algorithm performs well for $T_{p \max }$ prediction, and it overestimates slightly the $H_{s \max }$ results for TCs with lower $U_{10 \max }$ or smaller $r_{m}$.

The results in Fig. 4 are reproduced as lookup tables in the appendix (Table A1), separating the computations of the fetch and duration functions. For operational applications, $U_{10 \max }$ is given in knots $\left(\mathrm{kt}, 1 \mathrm{kt}=0.51 \mathrm{~m} \mathrm{~s}^{-1}\right), r_{m}$ in nautical miles (n mi, $1 \mathrm{n} \mathrm{mi}=1.852 \mathrm{~km}$,) $H_{s \max }$ in feet, and $T_{p \max }$ in seconds; $H_{s \max }$ and $T_{p \max }$ are rounded to the nearest integers.

\section{c. Limitations}

The algorithm of maximum wave height and wave period presented in this paper is based on the fetch- and duration-limited wave growth nature observed from analyses of simultaneous wind and wave observations in hurricane reconnaissance and research missions. These simultaneous wind and wave data provide the necessary information for constructing an effective fetch and duration model of the hurricane wind fields. Because of the limited number of datasets, the RMW is the only hurricane parameter in the fetch and duration model. The hurricane hunter may or may not pass through the location of maximum wind speed; there are inherent uncertainties in the values of the hurricane intensity and radius of maximum wind speed listed in Table 1.

As has been discussed in Hwang and Fan (2017), hurricane translation velocity $V_{h}$ has been identified as an important parameter impacting wave growth inside hurricanes (Young 1988, 1998; Bowyer and MacAfee 2005; MacAfee and Bowyer 2005; Young and Vinoth 2013) but the available hurricane hunter wind and wave datasets only cover a narrow range of $V_{h}$, so it was not included in the fetch and duration model developed in Hwang and Fan (2017).

It is recognized that there are many variables in hurricane properties aside from the hurricane intensity, radius of maximum wind, and translation velocity. Other factors such as wind field asymmetry, multiple eyewalls, rapidity of development, and track stability may all modify the properties of the hurricane wind field. The wind field modification leads to the modification of the surface waves generated. Some of these factors can be obtained from sources such as Automated Tropical Cyclone Forecasting System (ATCF) and the National 


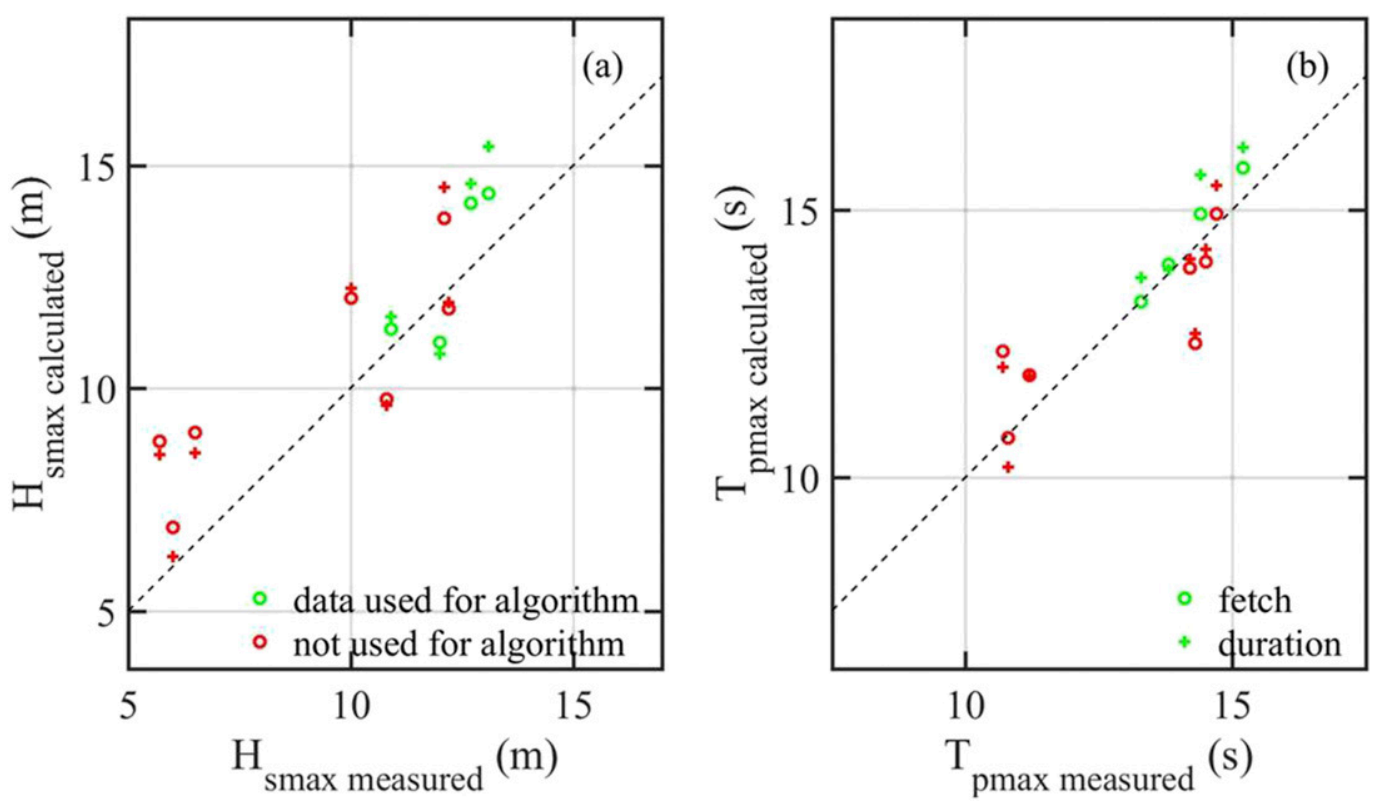

FIG. 3. Comparison of the predicted and observed (a) $H_{s \max }$ and (b) $T_{p \max }$. The results from the four datasets used in the algorithm development are shown with green symbols; those from seven datasets not used in the algorithm development are shown with red symbols.

Hurricane Center (NHC) "best track" hurricane database (HURDAT). Many publications have addressed the uncertainties of these sources. For example, Torn and Snyder (2012) estimated errors in track and intensity; Landsea and Franklin (2013) reported errors in track, intensity, and wind radii using NHC forecaster surveys; and Sampson et al. (2017) reported errors in radius of 34-kt winds (R34) estimates in NHC basins. The RMW is not listed in HURDAT, and its determination is not trivial (e.g., Mallen et al. 2005; Lajoie and Walsh 2008; Takagi and Wu 2016). We can expect an error of $15 \mathrm{n}$ mi on average and much larger values when there is a lack of observations or during eyewall replacement; an error estimate at $30 \%$ seems reasonable too. As an example, using the fetch function (see Table A1) for a hurricane with $U_{10 \max }=100 \mathrm{kt}$ and assuming $\pm 30 \% r_{m}$ uncertainty, the expected $H_{s \max }$ range for reported $20 \mathrm{n} \mathrm{mi} r_{m}$ is from about 31 to $34 \mathrm{ft}$ and the $T_{p \max }$ is $13 \mathrm{~s}$ (rounded to integers); the $H_{s \max }$ range increases to 41-70 ft and the $T_{p \max }$ values range to $15-20 \mathrm{~s}$ if the reported $r_{m}$ is $50 \mathrm{n} \mathrm{mi}$.

With the above reservations, the algorithm developed in this paper is expected to work well for hurricanes moving along stable tracks and at slow to moderate translation velocities, such that the effect of resonant propagation as detailed in Bowyer and MacAfee (2005) and MacAfee and Bowyer (2005) does not become a significant factor of wave growth.

\section{Scaling wind speed: Flight level versus $10-\mathrm{m}$ surface wind}

The maximum wave height and wave period algorithm described in this paper is based on the wind-wave growth functions with $U_{10}, H_{s}$, and $T_{p}$ serving as the scaling variables. The growth functions can be expressed as fetch, duration, and wave-age similarity functions: $\left[\eta_{\#}\left(x_{\#}\right), \omega_{\#}\left(x_{\#}\right)\right],\left[\eta_{\#}\left(t_{\#}\right), \omega_{\#}\left(t_{\#}\right)\right]$, and $\left[\eta_{\#}\left(\omega_{\#}\right)\right]$, respectively (Hwang and Wang 2004 and references therein). They can also be expressed with different scaling wind speeds such as the friction velocity $u_{*}$ or wind speed at the elevation equal to one-half the dominant wavelength $U_{\lambda / 2}$ (e.g., Hwang 2006 and references therein).

In the conventional approach to obtaining the windwave growth functions, the fetch and duration are known physical quantities, respectively, the unimpeded upwind distance from the measurement station to the land-water interface and the time lapse between wave measurement and the start of a wind event. Such physical measurements of fetch and duration cannot be applied to the TC wind fields. Instead, the effective fetch and duration of TC wind fields are obtained through reverse engineering, making use of the established wave growth functions and the simultaneously measured wind speed, significant wave height, and dominant wave period of the hurricane hunter datasets (Hwang and Fan 2017). As mentioned in section 1, Hwang and Fan (2017) 

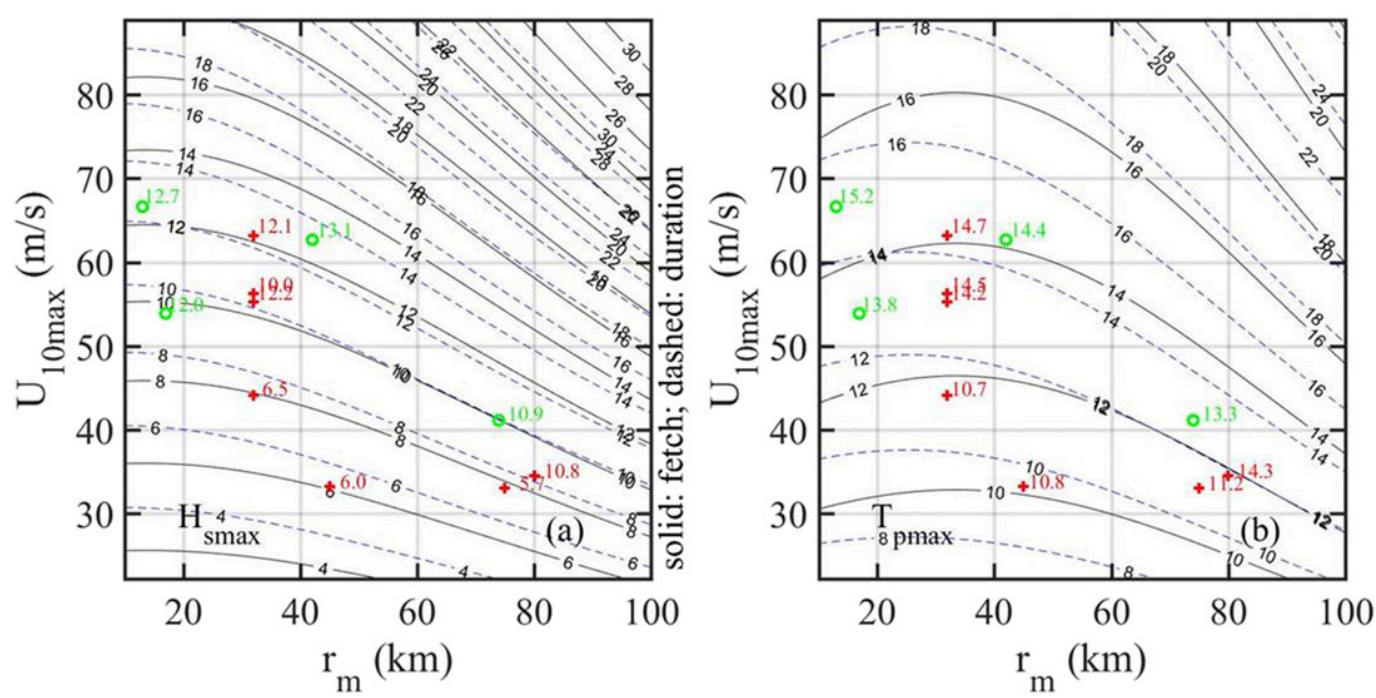

FIG. 4. Contour maps of (a) $H_{s \max }$ and (b) $T_{p \max }$ showing their dependence on $U_{10 \max }$ and $r_{m}$. Solid and dashed lines show the results computed with the fetch-limited and duration-limited functions, respectively. The red and green markers show $H_{s \max }$ and $T_{p \max }$ (with the corresponding values printed beside the markers) based on 11 hurricane reconnaissance and research missions. The four green markers are used in the algorithm development and the seven red markers are not used in the algorithm development.

misinterpreted the flight-level wind $U_{\mathrm{FL}}$ in the hurricane hunter datasets to be the surface wind $U_{10}$; it is necessary to discuss the impact of the scaling wind speed on the effective fetch and duration.

The relationship between flight-level and surface $(10 \mathrm{~m})$ wind velocities is of great interest, and significant improvement in the vertical wind profile has been achieved with the use of the GPS dropwindsonde system initiated in 1997 (e.g., Powell 1980; Dunion et al. 2003; Franklin et al. 2003; Uhlhorn and Black 2003; Uhlhorn et al. 2007). For example, Franklin et al. (2003) report that the dropwindsonde-derived mean wind profile near the eyewall is characterized by a broad maximum centered at $500 \mathrm{~m}$ above the surface. Below the maximum, the wind decreases logarithmically, with the altitude corresponding to the frictional boundary layer behavior. Above the maximum, the winds decrease because of the hurricane's warm core. A similar wind speed vertical profile is observed in the outer vortex with the maximum centered near $1000 \mathrm{~m}$ above the surface with reduced vertical wind gradients both above and below the maximum (their Figs. 8 and 9; Franklin et al. 2003). Their Table 2 lists the recommended operational wind adjustment factors $R_{U}$ for reconnaissance flight-level winds to the surface in the eyewall and the outer vortex. For 700 -and $850-\mathrm{hPa}$ flight levels (about 3100 and $1500 \mathrm{~m}$, respectively), $R_{U}=0.90$ and 0.80 for the eyewall, and 0.85 and 0.80 for the outer vortex.
For the four datasets analyzed in Hwang and Fan (2017), three of them include the flight-level information (I09, I12, and I14 during Hurricane Ivan in 2004, corresponding to entries 2-4 in Table 1). Figure 5a shows the histograms of the three datasets: the altitude $h$ of $\mathrm{I} 09$ is mostly at $1500 \mathrm{~m}$ with small fractions at 2500 and $3100 \mathrm{~m}$, I12 is mainly at $2500 \mathrm{~m}$, and I14 is mainly at $3100 \mathrm{~m}$ with a small fraction at $2600 \mathrm{~m}$. Figures $5 \mathrm{~b}-\mathrm{d}$ show the wind-wave growth function in terms of $\eta_{\#}\left(\omega_{\#}\right)$ for the three datasets, presented with both scalings using the flight-level wind speed and the adjusted surface wind using the adjustment factor $R_{U}=0.85$. The reference curves are the growth functions, derived by first- and secondorder fitting of measurements from nonhurricane fetch-limited experiments under quasi-steady wind velocity and near-neutral atmospheric stability conditions (Hwang and Wang 2004). The results from the two wind scalings show similar agreement with the reference curves. Using different scaling winds causes the data cloud to slide along the reference curves and does not alter the data scatter. The systematic deviation of the data from the reference curves is mainly associated with the azimuthal location of wind and wave measurements made inside the hurricane (Hwang 2016; Hwang and Walsh 2016; Hwang and Fan 2017).

The result from the $\eta_{\#}\left(\omega_{\#}\right)$ analysis indicates that the fetch- and duration-limited growth functions 

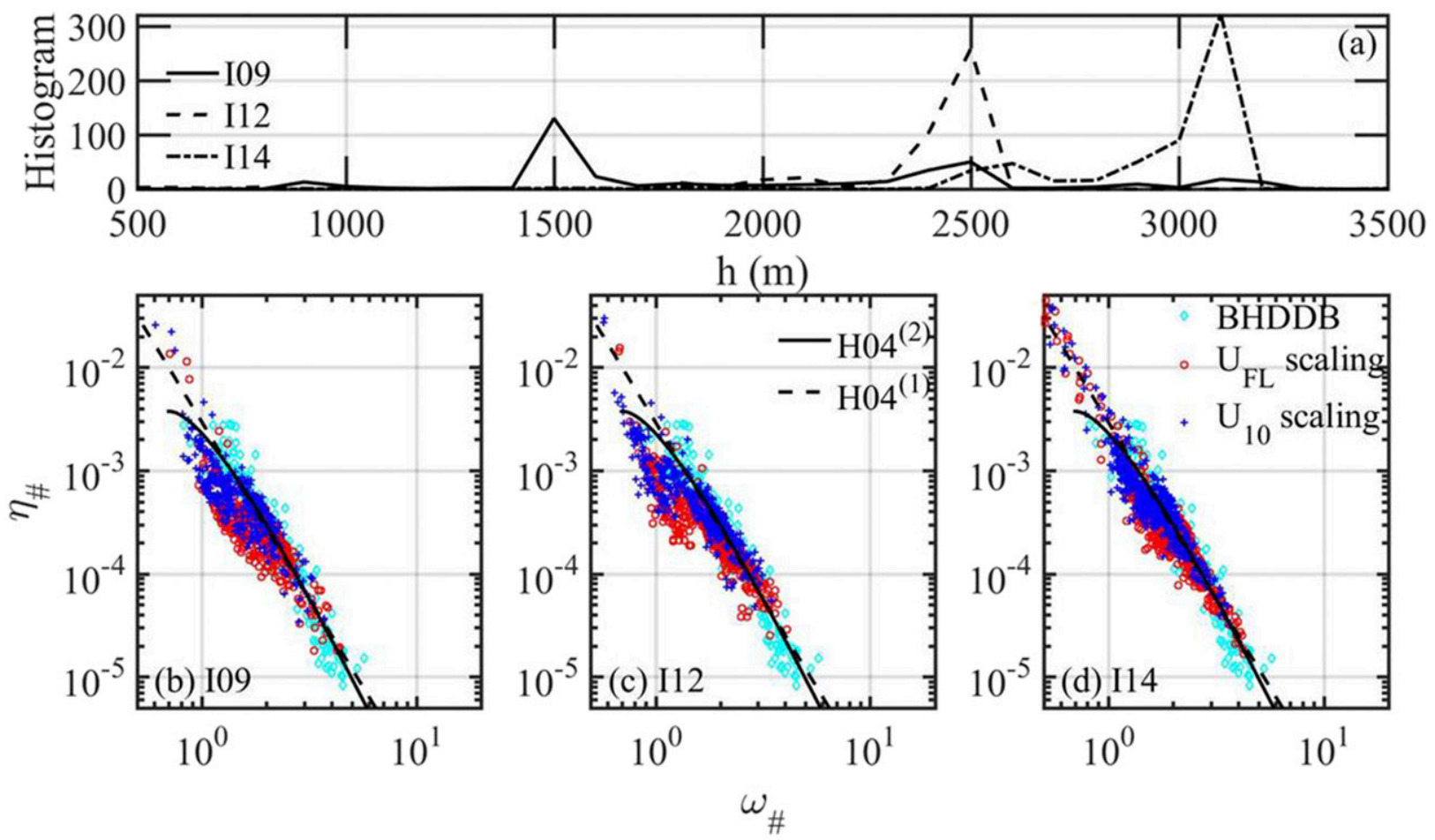

FIG. 5. (a) Histogram of flight altitudes in the three hurricane hunter datasets (I09, I12, and I14) during Hurricane Ivan in 2004. (b)-(d) The corresponding wind-wave growth functions in terms of the wave-age similarity $\eta_{\#}\left(\omega_{\#}\right)$ scaled with flight-level and surface winds.

[(1) and (2)] can be applied to hurricanes with surface wind speed $U_{10}$ scaling, as given in (3) and (4), or flightlevel wind speed $U_{\mathrm{FL}}$ scaling, that is, with $U_{10}$ replaced by $U_{\mathrm{FL}}$ in (3) and (4). Because the effective fetch $x_{f}$ and duration $t_{d}$ of the TC wind fields are derived from the wave growth functions, they will take on different values depending on the scaling wind speed used for the derivation. Specifically, the equations with $U_{10}$ scaling are given in Hwang and Fan (2017):

$$
\begin{aligned}
x_{\eta x 10} & =4.24 \times 10^{7} U_{10}^{-2.93} H_{s}^{2.47}, \\
x_{\omega x 10} & =2.29 \times 10^{4} U_{10}^{-2.22} T_{p}^{4.22} \text { and } \\
t_{\eta t 10} & =1.50 \times 10^{7} U_{10}^{-2.77} H_{s}^{1.88}, \\
t_{\omega t 10} & =4.81 \times 10^{4} U_{10}^{-2.22} T_{p}^{3.22} .
\end{aligned}
$$

With $U_{\mathrm{FL}}$ scaling, they become

$$
\begin{aligned}
x_{\eta x \mathrm{FL}} & =4.24 \times 10^{7} U_{\mathrm{FL}}^{-2.93} H_{s}^{2.47}, \\
x_{\omega x \mathrm{FL}} & =2.29 \times 10^{4} U_{\mathrm{FL}}^{-2.22} T_{p}^{4.22} \text { and } \\
t_{\eta t \mathrm{FL}} & =1.50 \times 10^{7} U_{\mathrm{FL}}^{-2.77} H_{s}^{1.88}, \\
t_{\omega t \mathrm{FL}} & =4.81 \times 10^{4} U_{\mathrm{FL}}^{-2.22} T_{p}^{3.22} .
\end{aligned}
$$

[Equations (19) and (21) rectify the mistakes of the coefficients in the wave period duration equation published in Hwang and Fan (2017); the computations presented in that paper used the correct equations.]

Figures $6 \mathrm{a}$ and $6 \mathrm{~b}$ show comparisons of the wave growth results of the hurricane and nonhurricane data expressed in terms of the fetch-limited similarity $\omega_{\#}\left(x_{\#}\right)$ and $\eta_{\#}\left(x_{\#}\right)$ and the duration-limited similarity $\omega_{\#}\left(t_{\#}\right)$ and $\eta_{\#}\left(t_{\#}\right)$. The scaling wind speed is $U_{10}$ in the nonhurricane data and $U_{\mathrm{FL}}$ for hurricanes. The hurricane data are sorted into the left- and right-hand sides of the hurricane; each half plane is further divided into inner and outer subgroups according to the distance from the hurricane center (30-80 and 80-200 km). Both hurricane and nonhurricane data groups show similar degrees of scatter, and they indeed can be described by the same wave growth functions shown with solid and dashed curves (Hwang and Wang 2004). The apparently larger data scatter of the results in the hurricane inner subgroups in both the left and right half planes is an indication of more complex wind and wave conditions as well as larger uncertainties in the wind and wave measurements in the region near the radius of maximum wind speed. In particular, the closer to the hurricane 


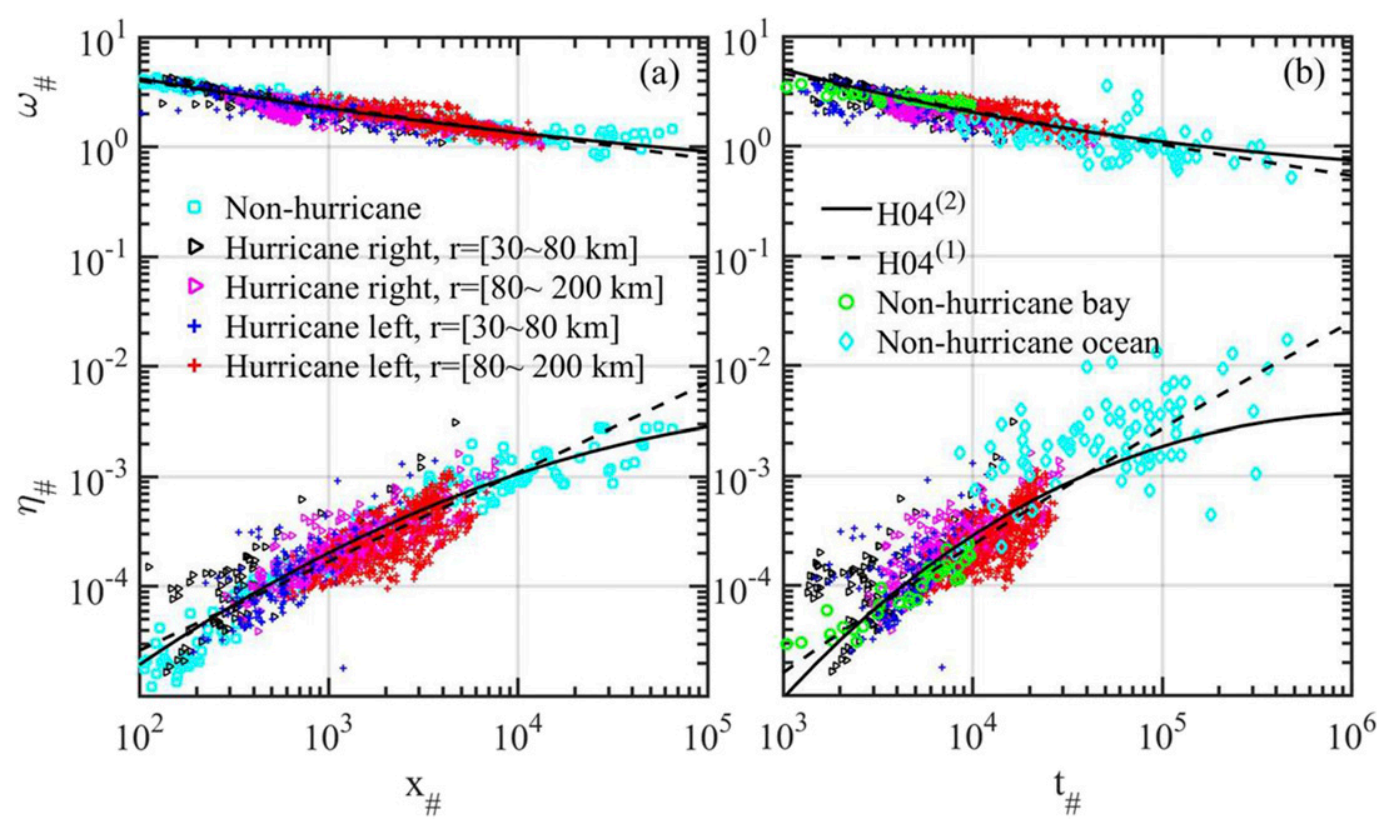

FIG. 6. The wind-wave growth functions in terms of (a) the fetch similarity $\eta_{\#}\left(x_{\#}\right)$ and $\omega_{\#}\left(x_{\#}\right)$ and (b) the duration similarity $\eta_{\#}\left(t_{\#}\right)$ and $\omega_{\#}\left(t_{\#}\right)$. The hurricane data are scaled with flight-level wind speed and sorted into the right and left groups referenced to the hurricane heading. Each group is further divided into two subgroups according to the distance from the hurricane center, as shown in the legend. The nonhurricane data are scaled with surface wind speed and include fetch-limited experiments and duration-limited experiments. The latter are further divided into open-ocean and sheltered-bay groups as described in Hwang and Wang (2004). The first- and second-order curves fitted through the fetch-limited experiments are shown with curves labeled $\mathrm{H} 04^{(1)}$ and $\mathrm{H} 04^{(2)}$ (Hwang and Wang 2004).

center, the farther away from the radius of maximum wind is the larger contribution of swell from nonlocal wind generation. For example, near the hurricane center, the wind speed is almost zero but the waves remain high and long.

The equations for retrieving $H_{s}$ and $T_{p}$ using the growth functions with $U_{\mathrm{FL}}$ as the scaling wind speed are

$$
\begin{aligned}
H_{s} & =8.10 \times 10^{-4} U_{\mathrm{FL}}^{1.19} x_{\eta x \mathrm{FL}}^{0.405}, \\
T_{p} & =9.28 \times 10^{-2} U_{\mathrm{FL}}^{0.526} x_{\omega x \mathrm{FL}}^{0.237} \text { and } \\
H_{s} & =1.55 \times 10^{-4} U_{\mathrm{FL}}^{1.47} t_{\eta t \mathrm{FL}}^{0.531}, \\
T_{p} & =3.53 \times 10^{-2} U_{\mathrm{FL}}^{0.690} t_{\omega t \mathrm{FL}}^{0.310} .
\end{aligned}
$$

The fetch and duration scaling model developed in Hwang and Fan (2017) is based on the flight-level wind speed (unintentionally), so (22) and (23) are used in the computations presented in section 4 . Because the maximum significant wave height and dominant wave period generally occur near the hurricane eyewall, the adjustment factor $R_{U}=0.9$ is used in the graphic presentations given with $U_{10}$ as the reference wind speed (Figs. 1, 2, and 4).

\section{Summary}

In this paper, we present an algorithm for predicting the maximum significant wave height and dominant wave period using the fetch and duration model of TC wind fields established with simultaneous wind and wave data acquired during four hurricane reconnaissance and research missions. The results of $H_{s \max }$ and $T_{p \max }$ show power dependence on the wind speed [(16) and (17)]. For the significant wave height, the wind speed exponents are about 1.19 and 1.47 based on the fetch and duration functions, respectively; for the dominant wave period, they are about 0.53 and 0.69 , respectively. The variation of the proportionality coefficients of the power functions can be expressed as second-order polynomials of $r_{m}$ [(17)]. The predicted values by the algorithm compare well with those observed during 11 hurricane reconnaissance and research missions, including the four used in the algorithm development (Figs. 3 and 4).

Acknowledgments. This work is sponsored by the Office of Naval Research (Funding Doc. N0001416WX00044). This paper is U.S. Naval Research Laboratory Publication Number JA/7260-17-0285. We are grateful for the comments and suggestions provided by Buck Sampson and an 
TABLE A1. Lookup tables of maximum significant wave height and dominant wave period (rounded to the nearest integer) derived from fetch and duration functions.

\begin{tabular}{|c|c|c|c|c|c|c|c|c|c|c|c|c|c|c|c|c|c|}
\hline & \multicolumn{8}{|c|}{$H_{s \max }(\mathrm{ft})$ fetch function } & & \multicolumn{8}{|c|}{$T_{p \max }(\mathrm{s})$ fetch function } \\
\hline & \multicolumn{8}{|c|}{$r_{m}(\mathrm{n} \mathrm{mi})$} & & \multicolumn{8}{|c|}{$r_{m}(\mathrm{n} \mathrm{mi})$} \\
\hline & & 10 & 20 & 30 & 40 & 50 & 60 & 70 & & & 10 & 20 & 30 & 40 & 50 & 60 & 70 \\
\hline \multirow[t]{13}{*}{$U_{10 \max }(\mathrm{kt})$} & 50 & 13 & 14 & 16 & 19 & 23 & 28 & 34 & $U_{10 \max }(\mathrm{kt})$ & 50 & 9 & 9 & 9 & 10 & 11 & 13 & 15 \\
\hline & 60 & 16 & 17 & 20 & 23 & 28 & 34 & 42 & & 60 & 10 & 10 & 10 & 11 & 12 & 14 & 16 \\
\hline & 70 & 20 & 21 & 24 & 28 & 34 & 41 & 50 & & 70 & 11 & 11 & 11 & 12 & 13 & 15 & 17 \\
\hline & 80 & 23 & 25 & 28 & 33 & 40 & 48 & 59 & & 80 & 11 & 11 & 12 & 13 & 14 & 16 & 19 \\
\hline & 90 & 27 & 28 & 32 & 38 & 46 & 56 & 68 & & 90 & 12 & 12 & 12 & 13 & 15 & 17 & 20 \\
\hline & 100 & 30 & 32 & 36 & 43 & 52 & 63 & 77 & & 100 & 13 & 13 & 13 & 14 & 16 & 18 & 21 \\
\hline & 110 & 34 & 36 & 41 & 48 & 58 & 71 & 86 & & 110 & 14 & 13 & 14 & 15 & 17 & 19 & 22 \\
\hline & 120 & 38 & 40 & 45 & 53 & 64 & 78 & 95 & & 120 & 14 & 14 & 14 & 16 & 17 & 20 & 23 \\
\hline & 130 & 41 & 44 & 49 & 58 & 71 & 86 & 105 & & 130 & 15 & 15 & 15 & 16 & 18 & 21 & 24 \\
\hline & 140 & 45 & 48 & 54 & 64 & 77 & 94 & 115 & & 140 & 15 & 15 & 16 & 17 & 19 & 22 & 25 \\
\hline & 150 & 49 & 52 & 59 & 69 & 84 & 102 & 124 & & 150 & 16 & 16 & 16 & 17 & 20 & 22 & 26 \\
\hline & \multicolumn{8}{|c|}{$H_{s \max }(\mathrm{ft})$ duration function } & & \multicolumn{8}{|c|}{$T_{p \max }(\mathrm{s})$ duration function } \\
\hline & \multicolumn{8}{|c|}{$r_{m}(\mathrm{n} \mathrm{mi})$} & & \multicolumn{8}{|c|}{$r_{m}(\mathrm{n} \mathrm{mi})$} \\
\hline$U_{10 \max }(\mathrm{kt})$ & 50 & 10 & 11 & 13 & 16 & 20 & 26 & 32 & $U_{10 \max }(\mathrm{kt})$ & 50 & 8 & 8 & 8 & 9 & 11 & 12 & 15 \\
\hline & 60 & 13 & 15 & 17 & 21 & 27 & 33 & 41 & & 60 & 9 & 9 & 9 & 10 & 12 & 14 & 17 \\
\hline & 70 & 17 & 18 & 22 & 27 & 34 & 42 & 52 & & 70 & 10 & 10 & 10 & 12 & 13 & 16 & 19 \\
\hline & 80 & 20 & 22 & 27 & 33 & 41 & 51 & 63 & & 80 & 11 & 11 & 11 & 13 & 15 & 17 & 20 \\
\hline & 90 & 24 & 27 & 32 & 39 & 49 & 61 & 75 & & 90 & 12 & 12 & 12 & 14 & 16 & 19 & 22 \\
\hline & 100 & 28 & 31 & 37 & 45 & 57 & 71 & 88 & & 100 & 12 & 13 & 13 & 15 & 17 & 20 & 24 \\
\hline & 110 & 33 & 36 & 42 & 52 & 65 & 81 & 101 & & 110 & 13 & 13 & 14 & 16 & 18 & 22 & 25 \\
\hline & 120 & 37 & 41 & 48 & 59 & 74 & 93 & 115 & & 120 & 14 & 14 & 15 & 17 & 19 & 23 & 27 \\
\hline & 130 & 42 & 46 & 54 & 67 & 83 & 104 & 129 & & 130 & 15 & 15 & 16 & 18 & 21 & 24 & 29 \\
\hline & 140 & 46 & 51 & 60 & 74 & 93 & 116 & 144 & & 140 & 16 & 16 & 17 & 19 & 22 & 25 & 30 \\
\hline & 150 & 51 & 57 & 67 & 82 & 103 & 129 & 159 & & 150 & 16 & 17 & 18 & 20 & 23 & 27 & 32 \\
\hline
\end{tabular}

anonymous reviewer. Datasets used in this analysis are given in the references cited. The processing codes and data segments can also be obtained by contacting the corresponding author.

\section{APPENDIX}

\section{Lookup Table of Maximum Wave Height and Wave Period}

Presented as a set of design values, Table A1 reproduces the results of Fig. 4, separating the computations of fetch and duration functions. For operational applications, $U_{10 \max }$ is given in knots, $r_{m}$ in nautical miles, $H_{s \max }$ in feet, and $T_{p \max }$ in seconds. The $H_{s \max }$ and $T_{p \max }$ values obtained by the fetch functions are displayed in the top half of the table. The corresponding values obtained by the duration functions are given in the bottom half. The $H_{s \max }$ and $T_{p \max }$ values are rounded to the nearest integers. It is not clear how far the power-law wind speed dependency and the second-order polynomial $r_{m}$ dependency can be applied. The maximum $U_{10}$ and $r_{m}$ in Table A1 are $150 \mathrm{kt}$ and $70 \mathrm{n} \mathrm{mi}$, respectively.

\section{REFERENCES}

Babanin, A. V., and Y. P. Soloviev, 1998: Field investigation of transformation of the wind wave frequency spectrum with fetch and the stage of development. J. Phys. Oceanogr., 28, 563-576, https:// doi.org/10.1175/1520-0485(1998)028<0563:FIOTOT>2.0.CO;2.

Bowyer, P. J., and A. W. MacAfee, 2005: The theory of trapped-fetch waves with tropical cyclones - An operational perspective. Wea. Forecasting, 20, 229-244, https://doi.org/10.1175/WAF849.1.

Burling, R. W., 1959: The spectrum of waves at short fetches. Dtsch. Hydrogr. Z., 12, 96-117, https://doi.org/10.1007/BF02019818.

Dobson, F., W. Perrie, and B. Toulany, 1989: On the deepwater fetch laws for wind-generated surface gravity waves. Atmos.-Ocean, 27, 210-236, https://doi.org/10.1080/ 07055900.1989 .9649334$.

Donelan, M. A., J. Hamilton, and W. H. Hui, 1985: Directional spectra of wind-generated waves. Philos. Trans. Roy. Soc. London, 315A, 509-562, https://doi.org/10.1098/rsta.1985.0054.

Dunion, J. P., C. W. Landsea, S. H. Houston, and M. D. Powell, 2003: A reanalysis of the surface winds for Hurricane Donna of 1960. Mon. Wea. Rev., 131, 1992-2011, https://doi.org/ 10.1175/1520-0493(2003)131<1992:AROTSW>2.0.CO;2.

Fan, Y., I. Ginis, T. Hara, C. W. Wright, and E. J. Walsh, 2009: Numerical simulations and observations of surface wave fields under an extreme tropical cyclone. J. Phys. Oceanogr., 39, 2097-2116, https://doi.org/10.1175/2009JPO4224.1.

Franklin, J. L., M. L. Black, and K. Valde, 2003: GPS dropwindsonde wind profiles in hurricanes and their operational 
implications. Wea. Forecasting, 18, 32-44, https://doi.org/10.1175/ 1520-0434(2003)018<0032:GDWPIH > 2.0.CO;2.

Hasselmann, K., and Coauthors, 1973: Measurements of windwave growth and swell decay during the Joint North Sea Wave Project (JONSWAP). Dtsch. Hydrogr. Z., A8 (Suppl.), 7-95.

— D. B. Ross, P. Müller, and W. Sell, 1976: A parametric wave prediction model. J. Phys. Oceanogr., 6, 200-228, https:// doi.org/10.1175/1520-0485(1976)006<0200:APWPM>2.0.CO;2.

Holland, G. J., 1980: An analytic model of the wind and pressure profiles in hurricane. Mon. Wea. Rev., 108, 1212-1218, https:// doi.org/10.1175/1520-0493(1980)108<1212:AAMOTW>2.0.CO;2.

— J. I. Belanger, and A. Fritz, 2010: A revised model for radial profiles of hurricane winds. Mon. Wea. Rev., 138, 4393-4401, https://doi.org/10.1175/2010MWR3317.1.

Hwang, P. A., 2006: Duration- and fetch-limited growth functions of wind-generated waves parameterized with three different scaling wind velocities. J. Geophys. Res., 111, C02005, https:// doi.org/10.1029/2005JC003180.

2016: Fetch- and duration-limited nature of surface wave growth inside tropical cyclones: With applications to air-sea exchange and remote sensing. J. Phys. Oceanogr., 46, 41-56, https://doi.org/10.1175/JPO-D-15-0173.1.

, and D. W. Wang, 2004: Field measurements of duration limited growth of wind-generated ocean surface waves at young stage of development. J. Phys. Oceanogr., 34, 2316-2326, https:// doi.org/10.1175/1520-0485(2004)034<2316:FMODGO>2.0.CO; 2; Corrigendum, 35, 268-270, https://doi.org/10.1175/JPO-2731.1.

— wind-generated surface waves inside tropical cyclones. J. Phys. Oceanogr., 46, 2605-2621, https://doi.org/10.1175/ JPO-D-16-0051.1.

- and Y. Fan, 2017: Effective fetch and duration of tropical cyclone wind fields estimated from simultaneous wind and wave measurements: Surface wave and air-sea exchange computation. J. Phys. Oceanogr., 47, 447-470, https://doi.org/ 10.1175/JPO-D-16-0180.1.

— - H. García-Nava, and F. J. Ocampo-Torres, 2011: Observations of wind wave development in mixed seas and unsteady wind forcing. J. Phys. Oceanogr., 41, 2343-2362, https:// doi.org/10.1175/JPO-D-11-044.1.

Lajoie, F., and K. Walsh, 2008: A technique to determine the radius of maximum wind of a tropical cyclone. Wea. Forecasting, 23, 1007-1015, https://doi.org/10.1175/2008WAF2007077.1.

Landsea, C. W., and J. L. Franklin, 2013: Atlantic hurricane database uncertainty and presentation of a new database format. Mon. Wea. Rev., 141, 3576-3592, https://doi.org/10.1175/ MWR-D-12-00254.1.

MacAfee, A. W., and P. J. Bowyer, 2005: The modeling of trappedfetch waves with tropical cyclones-A desktop operational model. Wea. Forecasting, 20, 245-263, https://doi.org/10.1175/ WAF850.1.

Mallen, K. J., M. T. Montgomery, and B. Wang, 2005: Reexamining the near-core radial structure of the tropical cyclone primary circulation: Implications for vortex resiliency. J. Atmos. Sci., 62, 408-425, https://doi.org/10.1175/JAS-3377.1.
Moon, I.-J., I. Ginis, T. Hara, H. L. Tolman, C. W. Wright, and E. J. Walsh, 2003: Numerical simulation of sea surface directional wave spectra under hurricane wind forcing. J. Phys. Oceanogr., 33, 1680-1706, https://doi.org/10.1175/2410.1.

Powell, M. D., 1980: Evaluations of diagnostic marine boundary layer models applied to hurricanes. Mon. Wea. Rev., 108, 757-766, https:// doi.org/10.1175/1520-0493(1980)108<0757:EODMBL >2.0.CO;2.

Sampson, C. R., E. M. Fukuda, J. A. Knaff, B. R. Strahl, M. J. Brennan, and T. Marchok, 2017: Tropical cyclone gale wind radii estimates for the western North Pacific. Wea. Forecasting, 32, 1029-1040, https://doi.org/10.1175/WAF-D-16-0196.1.

Sverdrup, H. U., and W. H. Munk, 1947: Wind, sea, and swell: Theory of relations for forecasting. U.S. Navy Hydrographic Office Tech. Rep. 1, 56 pp.

Takagi, H., and W. Wu, 2016: Maximum wind radius estimated by the $50 \mathrm{kt}$ radius: Improvement of storm surge forecasting over the western North Pacific. Nat. Hazards Earth Syst. Sci., 16, 705-717, https://doi.org/10.5194/nhess-16-705-2016.

Torn, R. D., and C. Snyder, 2012: Uncertainty of tropical cyclone best-track information. Wea. Forecasting, 27, 715-729, https:// doi.org/10.1175/WAF-D-11-00085.1.

Uhlhorn, E. W., and P. G. Black, 2003: Verification of remotely sensed sea surface winds in hurricanes. J. Atmos. Oceanic Technol., 20, 99-116, https://doi.org/10.1175/1520-0426(2003)020<0099: VORSSS $>2.0$.CO;2.

,-- J. L. Franklin, M. Goodberlet, J. Carswell, and A. S. Goldstein, 2007: Hurricane surface wind measurements from an operational stepped frequency microwave radiometer. Mon. Wea. Rev., 135, 3070-3085, https://doi.org/10.1175/ MWR3454.1.

Walsh, E. J., D. W. Hancock, D. E. Hines, R. N. Swift, and J. F. Scott, 1985: Directional wave spectra measured with the surface contour radar. J. Phys. Oceanogr., 15, 566-592, https:// doi.org/10.1175/1520-0485(1985)015<0566:DWSMWT>2.0.CO;2. rectional wave spectrum evolution from shoreline to fully developed. J. Phys. Oceanogr., 19, 670-690, https://doi.org/ 10.1175/1520-0485(1989)019<0670:AOOTDW >2.0.CO;2.

_ , and Coauthors, 2002: Hurricane directional wave spectrum spatial variation at landfall. J. Phys. Oceanogr., 32, 1667-1684, https:// doi.org/10.1175/1520-0485(2002)032<1667:HDWSSV>2.0.CO;2.

Wright, C. W., and Coauthors, 2001: Hurricane directional wave spectrum spatial variation in the open ocean. J. Phys. Oceanogr., 31, 2472-2488, https://doi.org/10.1175/1520-0485(2001)031<2472: HDWSSV $>2.0 . \mathrm{CO} ; 2$.

Young, I. R., 1988: Parametric hurricane wave prediction model. J. Waterw. Port Coastal Ocean Eng., 114, 637-652, https:// doi.org/10.1061/(ASCE)0733-950X(1988)114:5(637).

_ 1998: Observations of the spectra of hurricane generated waves. Ocean Eng., 25, 261-276, https://doi.org/10.1016/ S0029-8018(97)00011-5.

_ , and J. Vinoth, 2013: An "extended fetch" model for the spatial distribution of tropical cyclone wind-waves as observed by altimeter. Ocean Eng., 70, 14-24, https://doi.org/ 10.1016/j.oceaneng.2013.05.015. 